\title{
AUTONOMIA MUNICIPAL NO FEDERALISMO FISCAL BRASILEIRO: A Eficiência na Administração Tributária Municipal
}

\author{
MUNICIPAL AUTONOMY IN BRAZILIAN TAX FEDERALISM: \\ Efficiency in Municipal tax Administration
}

\author{
Albertiano Dias da Silva ${ }^{4}$ \\ Alex Dias da Silva ${ }^{5}$
}

Artigo recebido em: 14/11/2018.

Artigo aprovado em: 05/12/2018.

\begin{abstract}
Resumo: O objetivo deste artigo científico é analisar as principais características e arranjos da administração tributária dos Municípios brasileiros com a finalidade de buscar um modelo de eficiência para a concretização do princípio constitucional da autonomia dos entes federativos, sobretudo a autonomia municipal. Com a Constituição Federal de 1988 surgiu uma nova ordem jurídica que ocasionou, entre outras, a descentralização dos serviços públicos entre os entes federativos, sobretudo aumentando as atribuições de competências municipais. Abordaremos a função do Município no federalismo fiscal e as formas de efetivar o princípio da autonomia e autossuficiência. Estudaremos os principais tributos da competência constitucional tributária dos Municípios: ISS, IPTU, ITBI, taxas, contribuições de melhoria, contribuições de iluminação pública e etc. Destacaremos a importância das transferências e repasses intergovernamentais, sobretudo provenientes das esferas federal e estaduais. Conheceremos a forma de gerir o orçamento público, com o modelo de gerenciamento das receitas e despesas pelos instrumentos da legislação vigente. Verificaremos a estrutura e o modus operandi da administração tributária municipal ao fiscalizar e arrecadar, identificando as principais deficiências e desafios. E finalmente, quando da conclusão do estudo indicaremos as potenciais soluções para uma melhor eficiência na administração tributária visando a tornar mais efetiva a autonomia municipal no federalismo fiscal brasileiro.
\end{abstract}

Palavras-chave: Princípio da Autonomia. Administração Tributária. Municípios.

Abstract: The purpose of this article is to analyze the main characteristics and arrangements of the tax administration of the Brazilian Municipalities with the purpose of seeking an efficiency model for the realization of the constitutional principle of the autonomy of federative entities, especially municipal autonomy. With the Federal Constitution of 1988 a new legal order arose that caused, among others, the decentralization of public services between federative entities, above all increasing the attributions of municipal competences. We will address the role of the Municipality in fiscal federalism and the ways of implementing the principle of autonomy and self-sufficiency. We will study the main tributes of the constitutional tax jurisdiction of the Municipalities: ISS, IPTU, ITBI, rates, improvement contributions, public lighting contributions and etc. We will highlight the importance of intergovernmental transfers and transfers, especially from the federal and state levels. We will know how to manage the public budget, with the model of revenue and expenditure management by the instruments of the current legislation. We will

\footnotetext{
${ }^{4}$ Bacharel em Direito pela Universidade Estadual da Paraíba (UEPB), especialista em Direito Tributário pelo Instituto de Educação Superior da Paraíba (IESP) e em Gestão Pública (UEPB). Bacharel em Ciências Contábeis pela Universidade do Norte do Paraná (UNOPAR).

${ }^{5}$ Professor Efetivo do Instituto Federal da Paraíba (UFPB). Mestre em Engenharia Civil e Ambiental (UFPB). Bacharel em Direito pela Associação Paraibana de Ensino Renovado (ASPER).
} 
verify the structure and the modus operandi of the municipal tax administration when inspecting and collecting, identifying the main deficiencies and challenges. And finally, at the conclusion of the study, we will indicate the potential solutions for a better tax administration efficiency in order to make municipal autonomy more effective in Brazilian fiscal federalism.

Keywords: Principle of Autonomy. Tax administration. Counties.

\section{INTRODUÇÃO}

Na República Federativa do Brasil, a Constituição Federal de 1988 inaugurou uma nova ordem jurídica e estabeleceu entre os entes federativos estatais uma divisão de competências e atribuições. A descentralização dos serviços públicos ocasionou uma maior importância e participação dos Municípios na realização do bem comum e na implementação de políticas públicas. O cumprimento das novas demandas causou a necessidade de financiamento, o que veio acompanhado do crescimento das despesas. Importante lembrar que para a imensa maioria dos pequenos Municípios brasileiros existem grandes dificuldades na aferição de receita tributária suficiente que venha a suprir essas despesas, mesmo que haja fontes legais próprias de custeio. Esses pequenos Municípios, se analisarmos a fundo, dependem quase que exclusivamente de repasses e transferências intergovernamentais. Para efetivar a autonomia municipal e o federalismo exigem-se esforços de tais Municípios brasileiros no sentido de aumentar deveras a arrecadação tributária, buscando assim sua autossuficiência em face dos deveres do federalismo republicano.

Com a finalidade de extinguir esses problemas foi iniciado na década de 90, o debate sobre a reforma tributária objetivando que os Municípios se tornem autossuficientes ou pelo menos, amenizar a dependência das transferências intergovernamentais. No entanto, a eficiência da arrecadação municipal enfrenta alguns desafios como: falta de capacitação e conhecimento da realidade tributária municipal; o pessimismo e desinteresse quanto à possibilidade de promover a auto-sustentabilidade, e por último, a necessidade de um sistema de informações precisas e atualizadas que auxiliem a administração tributária a desempenhar melhor as suas atribuições de arrecadação e fiscalização.

A Constituição Federal em vigor, além de distribuir atribuições aos entes federativos, também definiu, precipuamente aos Municípios, instrumentos de arrecadação própria através dos tributos de sua competência e no que se compreende aponta também para a necessidade de investimentos dos edis na máquina fazendária. A Lei de Responsabilidade Fiscal (Lei Complementar $n^{\circ} 101$, de 04 de maio de 2000) foi um dos instrumentos legislativos que vieram também para ampliar a necessidade de gestão fiscal ao estabelecer parâmetros para que não se gaste mais do que se arrecada. A LRF impôs também restrições às despesas públicas e estimulou os governos dos entes federativos a utilizarem melhor suas bases de tributação com maior eficiência da administração tributária municipal. 
A metodologia utilizada neste trabalho foi a pesquisa bibliográfica, documental e o levantamento de dados. Usou-se uma abordagem explicativa, descritiva e demonstrativa de vários aspectos da tributação. Com base em conceitos e ideias de renomados autores que relacionam o tema, bem como de doutrinadores do Direito Constitucional, Tributário e Administrativo.

Com base no que foi exposto, o objetivo principal do trabalho é analisar o modelo de federalismo e tributação adotados no Brasil, as exações de competência municipal e o sistema de transferências intergovernamentais. As receitas municipais serão estudadas em relação à sua composição e à sua evolução.

\section{PRINCÍPIOS CONSTITUCIONAIS E O FEDERALISMO FISCAL}

A Constituição Federal de 1988 em seu artigo $1^{\circ}$ diz que a República Federativa do Brasil é formada pela união indissolúvel dos Estados e Municípios e do Distrito Federal, e constitui-se em Estado Democrático de Direito.

Da leitura do dispositivo constitucional decorre que nosso país é uma democracia fundada no alicerce da ordem jurídica e que adotou como tipo de governo a república e como forma de estado o federalismo.

Segundo CARRAZA (2013, p.66), "República é o tipo de governo, fundado na igualdade formal das pessoas, em que os detentores do poder político o exercem em caráter eletivo, representativo (de regra), transitório e com responsabilidade".

O fato de o Brasil ser uma República, onde impera a igualdade formal, denota que os mandatários eleitos exercem o poder de forma que direitos e deveres devem ser iguais para todos os cidadãos, e quanto à tributação com benefícios e encargos também isonômicos. Todos devem sujeitar-se a tributação (com ressalvas quanto às imunidades), uma vez que o princípio republicano faz, especificamente, quanto à tributação, com que se alcance a isonomia e justiça, já que os indivíduos que se encontram na mesma situação de igualdade econômica e realizam a mesma hipótese de incidência devem ser igualmente gravados.

Além da forma de governo republicano, a Constituição Federal também manteve a forma de estado Federal. Composta pelos entes federativos: União, 26 Estados-membros, Distrito Federal e 5570 Municípios (IBGE, 2013) que são possuidores de autonomia política e administrativa, além de atribuições e competências próprias e comuns. Não existem níveis hierárquicos entre esses entes, no entanto existem competências distintas enumeradas pela própria Constituição.

Quanto aos Municípios, a descentralização típica da Carta Magna de 1988 deu capacidade própria para arrecadação tributária frente ao custeio e financiamento de medidas e políticas que visem a dar corpo a suas atribuições constitucionais elencadas nos artigos 29, 29-A e 30 da Constituição Federal. A Carta Magna 
usou uma fórmula abrangente autorizando os Municípios a legislarem sobre assuntos de interesse local. Além das competências comuns do art. 23 da Lei Suprema que também abarcam os Municípios.

O Sistema Tributário Nacional esquematizado em suas bases pela Constituição Federal em vigor define e atribui as competências tributárias e as transferências intergovernamentais (repartição constitucional das receitas tributárias) que visam a compor as fontes de custeio do funcionamento da máquina estatal por parte de seus diferentes entes. Sendo assim cada nível governamental terá seus tributos próprios e a divisão de repasses para Estados e Municípios incapazes de financiarem suas atividades utilizando-se apenas de sua arrecadação tributária. O Poder Constituinte assim fez, pois há uma concentração mais elevada de tributos nas esferas federal (União) e estadual. Para atenuar esta discrepância, decidiu-se que algumas das receitas tributárias deveriam ser repartidas com os Municípios.

\section{COMPETÊNCIA TRIBUTÁRIA DOS MUNICÍPIOS}

O Município, segundo os artigos 18, 29 e 30 da Constituição em vigor, é pessoa jurídica de direito publico interno, dotada de competência legislativa própria e exclusiva exercida por meio da elaboração da Lei Orgânica Municipal e das demais leis municipais.

A instituição e arrecadação dos tributos da competência do poder público municipal consolidam o princípio da autonomia e dá efetividade ao federalismo fiscal, em relação às outras pessoas políticas estatais. Portanto, os Municípios têm o pleno exercício das competências tributárias.

Entre os tributos de competência dos Municípios instituídos pela $\mathrm{CF} / 88$, temos os impostos sobre a propriedade predial e territorial urbana (IPTU), impostos sobre a prestação de serviços de qualquer natureza (ISS ou ISSQN) e impostos sobre a alienação de bens imóveis (ITBI). Além da cobrança de taxas pelo exercício do poder de polícia e pela prestação de serviços, de contribuições de melhoria e contribuições para o custeio da iluminação pública. Veremos adiante a especificação de cada um deles.

\subsection{Imposto sobre Serviços de Qualquer Natureza - ISS ou ISSQN}

O Imposto sobre Serviços de Qualquer Natureza - ISS previsto na CF/88 no artigo 156, inciso III, é o imposto municipal que tem como fato gerador a prestação de serviços, incidindo sobre as atividades definidas na lista especificada na Lei Complementar $n^{\circ} 116$ de 31 de julho de 2003, que inclui dentre outros os serviços prestados por profissionais liberais (contadores, advogados, engenheiros, etc.), serviços educacionais, hospedagem, serviços bancários, fornecimento de mão de obra, serviços de reparação e manutenção entre outros. A base de cálculo do ISS é o preço do serviço, ou seja, a renda bruta. Excepcionalmente, em alguns casos, como na construção civil, é abatido o valor dos insumos. 
A referida Lei Complementar $n^{\circ} 116$ fixa a alíquota máxima do ISS em 5\% (cinco por cento), e a mínima em 2\% (dois por cento), conforme o artigo 88, do Ato das Disposições Constitucionais Transitórias, da Constituição Federal.

O ISS deve ser pago ao Município em que o serviço é positivamente prestado, ainda que o estabelecimento prestador esteja situado em outro Município.

\subsection{Imposto sobre a Propriedade Predial e Territorial Urbana-IPTU}

O Imposto sobre a Propriedade Predial e Territorial Urbana - é definido pelo artigo 156, inciso I da Constituição de 1988, o IPTU incide sobre a propriedade, o domínio útil ou a posse de propriedade imóvel localizada em zona urbana ou extensão urbana e tem como base de cálculo o valor venal do imóvel (valor de mercado).

O imposto tem seu lançamento fiscal iniciado a partir de um cadastro imobiliário e de um sistema de dados que elenca valores, elaborados pelos Municípios e que precisam ser permanentemente atualizados.

O IPTU, geralmente, é uma das maiores fontes arrecadatórias municipais, sendo muitas vezes a principal origem das receitas tributárias em Municípios médios ou Municípios de potencial turístico e de veraneio, precipuamente quando o ISS possui menor base de contribuintes. Não existe padronização nos procedimentos de cadastro e de cálculo do valor venal dos imóveis, sendo muito corriqueiro e usual percebermos Municípios onde o valor venal lançado para os imóveis pode representar percentuais ínfimos com relação ao valor real de mercado. Isso devido à ineficiência de muitas administrações tributárias municipais, ou mesmos por falta de interesse dos gestores em exercer a plenitude de sua competência tributária. A alíquota utilizada é estabelecida pelo legislador municipal, variando conforme o Município que é, em média, de $1 \%$.

O IPTU, além da função fiscal, com fins arrecadatórios tem também sua função social. O artigo 182 da Constituição Federal de 1988 define esta função ao afirmar que a propriedade privada deve atender aos fins sociais, sendo o mesmo artigo regulado e complementado pelo Estatuto das Cidades (Lei $\mathrm{n}^{\circ}$ 10.257, de 10 de julho 2001), que estabeleceu as diretrizes gerais da política urbana e regulamentando esta função social e estabelece uma série de instrumentos urbanísticos a serem aplicados pelas prefeituras como forma de sua promoção. Trata-se aqui de evitar também os interesses especulativos dos proprietários de imóveis que visam unicamente à valorização e ganho patrimonial em terrenos e imóveis ociosos. Uma das medidas é a possibilidade da cobrança do IPTU progressivo no tempo que determina a cobrança progressiva nas propriedades privadas urbanas que não estejam, efetivamente, cumprindo sua função social para que possa ser gradativamente mais onerada, com um valor crescentemente superior ao valor de base de cálculo. Sendo assim o Estatuto das Cidades (Parágrafo $1^{\circ}$ do Artigo $7^{\circ}$, Seção III da Lei no 10.257 , de 10 de julho 2001), 
prevê a alíquota máxima em até $15 \%$ a ser aplicada para cobrança do IPTU progressivo no tempo. Esta medida tem dois efeitos práticos sobre os especuladores, a rigor, visa a fazer com que o proprietário pague uma exação tributária maior ao Município, ou o tenha que vender ou ainda interromper o processo especulativo do imóvel.

\subsection{Imposto sobre a Transmissão de Bens Imóveis - ITBI}

O imposto sobre transmissão "inter vivos", a qualquer título, por ato oneroso, de bens imóveis, por natureza ou acessão física, e de direitos reais sobre imóveis, exceto os de garantia, bem como cessão de direitos a sua aquisição, mais conhecido como ITBI. É mais um tributo de competência municipal e está previsto no Art.156, II, da Constituição Federal, e nos artigos 32 a 42 do Código Tributário Nacional (Lei ${ }^{\circ}$ 5. 172, de 25 de outubro de 1966) e ainda na legislação tributária municipal.

Referida exação incide sobre a transferência da propriedade ou domínio útil dos imóveis e, da mesma forma que o IPTU, tem como base de cálculo o valor venal do imóvel. É atribuição do Município definir a alíquota do ITBI em lei ordinária municipal, que pode alcançar o limite máximo de $2 \%$ fixado por lei complementar. A função do ITBI é predominantemente fiscal, ou seja, arrecadatória visando a suprir os cofres públicos de recursos financeiros.

\subsection{Taxas}

A Constituição da República no artigo 145, II, bem como o art.77 do CTN (Lei n5.172, de 25 de outubro de 1966) confere aos Municípios a competência para instituir taxas, em razão do exercício do poder de polícia ou pela utilização, efetiva ou potencial, de serviços públicos específicos e divisíveis, prestados ao contribuinte ou postos a sua disposição. As taxas são instituídas através de lei ordinária municipal em cumprimento ao princípio da legalidade tributária.

Os contornos da definição constitucional deixam claro que as taxas são tributos retributivos ou contraprestacionais, uma vez que não podem ser cobradas sem que o Estado exerça o poder de polícia ou preste ao contribuinte, ou coloque à sua disposição, um serviço público específico e divisível. (ALEXANDRE, 2013, p. 26).

Neste sentido, existem taxas de polícia e de serviços.

Taxas de polícia ocorreram quando o fato gerador decorrer da atividade administrativa, verificado pelo conceito do artigo 78 do CTN: 
Art. 78-Considera-se poder de polícia atividade da administração pública que, limitando ou disciplinando direito, interesse ou liberdade, regula a prática de ato ou abstenção de fato, em razão de interesse público concernente à segurança, à higiene, à ordem, aos costumes, à disciplina da produção e do mercado, ao exercício de atividades econômicas dependentes de concessão ou autorização do Poder Público, à tranquilidade pública ou ao respeito à propriedade e aos direitos individuais ou coletivos.

Assim são exemplos de taxas de polícia, as de fiscalização e as de controle municipal.

Taxas de serviços é a cobrança de exação financeira a pessoa jurídica ou privada para usar certos serviços executados pela administração pública. Na definição do art. 79 do CTN esses serviços caracterizam-se pela divisibilidade e especificidade. Sendo específicos, quando possam ser destacados em unidades autônomas de intervenção, de utilidade ou de necessidades públicas, e sendo divisíveis quando suscetíveis de utilização separadamente, por parte de cada um dos seus usuários. Logo contribuinte sabe por quais serviços estará pagando. São exemplos de taxas de serviços, a taxa de coleta de lixo, a taxa de emissão de documentos, taxas de licenciamento, e alvarás de funcionamento entre outras.

\subsection{Contribuição de Melhoria}

Prevista no art. 145, III, da Constituição Federal, bem como nos artigos 81 e 82 do CTN, é uma exação cuja obrigação tem por fato gerador uma situação que representa um benefício especial auferido pelo contribuinte, qual seja uma obra pública que tem como consequência a valorização dos imóveis pertencentes aos potenciais contribuintes.

De acordo com Alexandre (2013), o fato gerador da contribuição de melhoria não é a realização da obra, mas sim sua consequência, explicita o autor no tocante à valorização imobiliária.

Entre os tributos municipais, o de menor expressão é a contribuição de melhoria, cuja finalidade, como já visto antes, é a compensação do custo de obra executada pelo poder público, da qual infere-se valorização imobiliária. Geralmente, a contribuição de melhoria só há sido cobrada em compensação às obras de pavimentação de vias públicas executadas pelas prefeituras. Sua cobrança é regulada pelo Decretolei 195, de 24 de fevereiro de 1967, cabendo ao Município a sua instituição por meio de lei ordinária.

\subsection{Contribuição para o Custeio do Serviço de Iluminação Pública - COSIP}

O artigo 149-A da Constituição federal de 88 institui a possibilidade de cobrança pelos Municípios e o Distrito Federal de contribuição para o custeio do serviço de iluminação pública - COSIP, na forma da 
lei, observado o disposto no art. 150, I e III (princípios da legalidade e anterioridade anual e nonagesimal). Podendo a cobrança da COSIP ser feita na própria fatura de consumo de energia elétrica.

A COSIP surgiu após os Municípios reclamarem a perda de grande fatia de arrecadação devido à extinção da antiga Taxa de Iluminação Pública (julgada inconstitucional pelo Supremo Tribunal Federal), pressionaram o Congresso Nacional, que através da Emenda Constitucional n. ${ }^{\circ} 39$ de 2002, autorizou a criação da referida contribuição. Houve unicamente a mudança da denominação de taxa de iluminação pública para contribuição de iluminação pública.

Cabe aos Municípios instituir a exação através de lei ordinária que definirá o fato gerador, alíquotas, base de cálculo e sujeitos passivos entre outros critérios.

\section{TRANSFERÊNCIAS INTERGOVERNAMENTAIS PARA OS MUNICÍPIOS}

Existem três tipos de transferências intergovernamentais: as transferências constitucionais e legais, que são obrigatórias, e as voluntárias, comumente conhecidas como convênios, contratos de repasse ou outros ajustes. As transferências constitucionais federais são as que ocasionam um maior impacto na grade de recursos para os Municípios e têm grande importância, já que tem a finalidade de efetivar o desenvolvimento de políticas públicas e melhorar a qualidade da gestão local. A partir do momento que passam a integrar a receita desses Municípios, serão administradas precipuamente, em regra, por esses, como recursos próprios.

\subsection{Transferências Constitucionais}

São as parcelas das receitas federais ou estaduais arrecadadas pela União e Estados e repassadas aos Municípios, conforme o caso. A divisão da receita proveniente da arrecadação de impostos ou também chamadas de repartições das receitas tributárias entre os entes federados representa uma das soluções para diminuir as desigualdades regionais e promover o equilíbrio socioeconômico entre os Municípios brasileiros. Estas transferências são vinculadas e acontecem em prazos estabelecidos por lei.

A Constituição Federal ao estabelecer o Sistema Tributário Brasileiro diferencia a repartição das receitas tributárias e transferências. Nesse sentido, destacamos o pensamento de Alexandre (2013, p. 638):

Para atingir a autonomia financeira necessária à efetividade do poder de auto-organização e normatização, autogoverno e autoadministração, o legislador constituinte brasileiro se utilizou de duas técnicas de repartição de renda: a atribuição de competência tributária própria (discriminação por fonte) e a participação dos entes menores na receita arrecadada pelos entes maiores (discriminação por produto). 
De outra forma, significa dizer que os Municípios possuem, para efetivar as necessidades das suas populações por serviços públicos, de recursos das receitas com origem nas cobranças dos tributos de sua competência das transferências de recursos da União, e do Estado em cujo território está inserido o Município.

As transferências podem ser regulares ou não. O funcionamento das regulares - ou constitucionais está definido pela Constituição e pela legislação complementar, que determinam as regras de distribuição e repasse. A distribuição das transferências não regulares - ou negociadas - se faz por meio de convênios e de acordo com o programa da agência administradora. A principal característica das transferências negociadas é o condicionamento da utilização dos recursos. (TRISTÃO, 2003, p. 109)

Veremos adiante as principais formas de repartição de receitas entre os entes federativos em escalada vertical, a começar pelas receitas federais aos Municípios.

\subsubsection{Repartição das Receitas Tributárias Federais (da União) para os Municípios}

No tocante à repartição das receitas federais, destacamos que o repasse ocorre da União para os Municípios e compreende os seguintes casos:

\subsubsection{Fundo de Participação dos Municípios (FPM)}

É o tipo de transferência intergovernamental na qual ocorre o repasse de recursos financeiros da União (Governo Federal) para os Municípios brasileiros, prevista na CF, Art. 159, inciso I, alíneas $b$ e $d$ :

Art. 159. A União entregará:

I - do produto da arrecadação dos impostos sobre renda e proventos de qualquer natureza e sobre produtos industrializados quarenta e oito por cento na seguinte forma:

b) vinte e dois inteiros e cinco décimos por cento ao Fundo de Participação dos Municípios;

d) um por cento ao Fundo de Participação dos Municípios, que será entregue no primeiro decêndio do mês de dezembro de cada ano.

Ou seja, trata-se de $22,5 \%+\mathbf{1 \%}$ da arrecadação do IPI e do IR já excluindo a parcela do Imposto de Renda Retido na Fonte-IRRF que pertence integralmente aos Municípios.

O principal critério a ser atendido para a distribuição dessas verbas é apurado, sobretudo de acordo com o número de habitantes, sendo assim fixadas faixas populacionais, cabendo a cada uma dessas faixas um coeficiente individual, estes dados são estimados em pesquisas realizadas pelo Instituto Brasileiro de Geografia e Estatística - IBGE. Os critérios atualmente utilizados para o cálculo dos coeficientes de 
participação dos Municípios estão baseados na Lei n. ${ }^{\circ}$. 5.172/66 (Código Tributário Nacional) e no DecretoLei N. ${ }^{\circ} 1.881 / 81$. Além de que a Lei Complementar 62/89 determina que os recursos do Fundo de Participação dos Municípios devem ser transferidos nos dias 10, 20 e 30 de cada mês, como vimos anteriormente na citação do mandamento constitucional das receitas oriundas da arrecadação do IR e IPI dos dez dias anteriores a transferência.

$\mathrm{Na}$ apuração do montante de destinação do FPM é necessário ponderarmos separadamente as capitais e os demais Municípios. Considerando que para as unidades capitais serão transferidos $10 \%$ e para as outras cidades os $90 \%$ restantes do montante constitucional de repasse da transferência.

\subsubsection{Repartição de Receitas Decorrentes do Imposto Territorial Rural - ITR}

O Imposto territorial Rural-ITR de competência da União é previsto no art.153, VI, da Constituição Federal e nos artigos 29, 30 e 31 do CTN tem como fato gerador a propriedade, o domínio útil ou a posse de imóvel por natureza, localizado fora da zona urbana do Município. A base de cálculo do ITR é o valor venal da terra nua, ou seja, o valor fundiário, apurado ao final do exercício anterior ao de ocorrência do fato gerador. Cabe aos Municípios 50\% do valor correspondente ao montante da arrecadação fiscal do ITR quando cobrado pela União, no entanto, na hipótese de ocorrência do art. $153, \S^{\circ}$, III da CF quando fiscalizados e cobrados pelos Municípios, por convênio com a União, poderão os Municípios ficar com $100 \%$ (totalidade) dos recursos provenientes do ITR.

\footnotetext{
O desempenho do ITR é sofrível. Sua arrecadação é dificultada por problemas técnicos e políticos. De um lado, depende da existência de um cadastro nacional de propriedades rurais, de outro lado, depende da existência de vontade política de cobrar o tributo. Como resultado o ITR acaba sendo um imposto que gera altos custos de arrecadação e praticamente nenhuma receita. (TRISTÃO, 2003, p.116).
}

Além da função fiscal, o ITR possui função extrafiscal. Sendo um meio de auxiliar o poder público com informação referente à propriedade rural e ao uso da terra e a função social da propriedade territorial rural combatendo os latifúndios improdutivos.

\subsubsection{Repartição da Receita Decorrentes do Imposto sobre operações Financeiras em Ouro - IOF-Ouro}

Previsto na $\mathrm{CF} / 88$ em seu artigo $153, \S 5^{\circ}$, inciso II:

Art. 153. Compete à União instituir impostos sobre:

V - operações de crédito, câmbio e seguro, ou relativas a títulos ou valores mobiliários;

$\S 5^{\circ}$ - O ouro, quando definido em lei como ativo financeiro ou instrumento cambial, sujeita-se

exclusivamente à incidência do imposto de que trata o inciso $\mathrm{V}$ do "caput" deste artigo, devido na 
operação de origem; a alíquota mínima será de um por cento, assegurada a transferência do montante da arrecadação nos seguintes termos:

II - setenta por cento para o Município de origem.

Portanto a Constituição Federal prevê que o ouro, quando definido em lei como ativo financeiro ou instrumento cambial, estará sujeito exclusivamente à incidência do Imposto sobre Operações Financeiras IOF, de competência da União, com uma alíquota mínima de 1\%. E do total de recursos arrecadados pela cobrança do IOF-Ouro produzidos naquele Município, 70\% destinam-se aos Municípios de origem. Obedecendo a regulamentação da Lei n ${ }^{\circ} 7.766$ de 1989.

Oportuno comentar que a arrecadação do IOF-Ouro é ínfima e não é uma fonte de verbas de relevância sequer para os Municípios onde existe a exploração de minas e jazidas do mineral.

\subsubsection{Fundo de Compensação pela Exportação de Produtos Industrializados - FPEX}

A imunidade das Exportações de produtos e serviços frente ao ICMS decorrente do art. 155, $\S 2^{\circ}$, inciso X, alínea a da Constituição, justificas-se nas palavras de Ricardo Alexandre, pois:

\footnotetext{
A regra é mais uma das que compõem o esforço de exportação do Estado Brasileiro, mas traz prejuízo para os Estados e ao Distrito Federal, pois, para estes, seria melhor que a circulação de mercadorias tivesse por destinatário alguém domiciliado no país, visto que, nesse caso, haveria a incidência do ICMS, com o consequente carreamento de recursos aos cofres públicos estaduais e distritais. (ALEXANDRE, 2013, p.651).
}

O artigo 159, inciso II, $\S 3^{\circ}$, da Constituição Federal prevê o ressarcimento aos Estados e Municípios pela desoneração das exportações de produtos industrializados do Imposto sobre Circulação de Mercadorias e Serviços. Esse fundo é composto por $10 \%$ da arrecadação do Imposto sobre Produtos Industrializados, que é distribuído aos Estados exportadores de modo proporcional ao valor exportado, observando-se o limite máximo de $20 \%$ para cada um. Do montante repassado aos Estados, 25\% são destinados a seus Municípios, seguindo a mesma sistemática dos repasses da Quota-parte do ICMS que será visto em tópico posterior. Ainda segundo Ricardo Alexandre (2013, p.651), quanto aos Municípios:

\footnotetext{
A regra é decorrência lógica do fato de o fundo servir como compensação à desoneração do ICMS nas exportações, que também prejudica os Municípios, os quais deixam de receber o repasse dos $25 \%$ constitucionais referentes a quota-parte ICMS.
}

\subsubsection{Repartição de Receitas Tributárias dos Estados para os Municípios}

O repasse ocorre do Estado-membro para os Municípios englobados em seu território e abarca os seguintes casos: 


\subsubsection{Quota-parte do ICMS}

O artigo 158, Inciso IV da CF/88 determina que os Estados devem repassar aos Municípios compreendidos em seu território $25 \%$ (vinte e cinco por cento) do produto da arrecadação do Imposto sobre Circulação de Mercadorias e Serviços de transporte interestadual e intermunicipal e comunicação de competência estadual (Art. 155, inciso II da CF/88).

Com relação aos critérios de distribuição da Quota-parte do ICMS, a Constituição Federal prevê no art. 158, parágrafo único, que, pelo menos, $75 \%$ (setenta e cinco por cento ou três quartos) dos recursos sejam rateados proporcionalmente ao valor adicionado gerado no próprio Município e que os restantes $25 \%$ (vinte e cinco por cento ou um quarto) sejam distribuídos segundo critérios estabelecidos em lei estadual. Nota-se que a finalidade desse regramento é beneficiar, sobretudo, os Municípios que mais contribuem quando da arrecadação do ICMS, haja vista a destinação de três quartos do montante arrecadado. Quanto aos outros $25 \%$ do montante da arrecadação, possuem os Estados autonomia através de lei própria para estabelecer os critérios de repartição, devendo observar, sobretudo os critérios de justiça e procurar minimizar desigualdades sociais e regionais.

\subsubsection{Repartição decorrente da arrecadação do Imposto sobre a Propriedade de Veículos Automotores - IPVA dos Estados para os Municípios}

A Constituição Federal de 1988 em seu artigo 158, inciso III, diz que pertence, aos Municípios, cinquenta por cento (50\%) do produto da arrecadação do imposto do Estado sobre a propriedade de veículos automotores licenciados em seus territórios. Sendo assim devem os Estados repassar a cada Município a metade da receita decorrente da arrecadação do IPVA que são licenciados em seus respectivos territórios. A título de exemplo, se um veículo é licenciado no Município de Mulungu no Estado da Paraíba, a metade do valor pago, ou seja, 50 \% do IPVA será entregue ao Município de Mulungu pelo Estado da Paraíba, ficando este último com os restantes $50 \%$ do montante.

\subsection{Transferências Legais}

Constitui a transferência de recursos orçamentários que são regulados por leis especificas. "Existem duas modalidades de transferências legais, a saber: a que a aplicação dos recursos repassados não está vinculada a um fim específico; e a que a aplicação dos recursos repassados está vinculada a um fim específico". (ABRANTES, 2010, p.100). 
No caso do repasse não vinculado o ente municipal detém a discricionariedade, podendo utilizar o recurso da maneira que bem lhe aprouver. São recursos livres, ou seja, recursos que a prefeitura poderá aplicar em qualquer tipo de despesa (folha de pagamento de pessoal, água, material de escritório, telefone, etc.). Quanto ao repasse vinculado, a transferência legal visa a cumprir a sua finalidade, o fim específico. Essa modalidade de transferência legal tem sido usada para repassar verbas aos Municípios em substituição aos convênios.

Os recursos vinculados podem ser decorrentes de transferências automáticas ou de transferências de fundo a fundo.

\title{
4.2.1Transferências Automáticas
}

As transferências automáticas são aquelas que correm com programas da área de Educação, senão vejamos:

\begin{abstract}
Consistem no repasse de recursos financeiros sem a utilização de convênio, ajuste, acordo ou contrato, mediante o depósito em conta corrente específica, aberta em nome do beneficiário. Essa forma recursos em determinados programas da área de Educação. As Medidas Provisórias n. 2.17836, de 24 de agosto de 2001 e n. 173, de 16 de março de 2004, como a Lei n. 10.219, de 11 de abril de 2001, disciplinam o emprego da transferência automática. Os programas em que se operam as transferências automáticas estão distribuídos no âmbito do Fundo Nacional de Desenvolvimento da Educação (FNDE). Atualmente, cinco programas permitem repasses da esfera federal à municipal. São eles: Programa Nacional de Alimentação Escolar (PNAE); Programa Dinheiro Direto na Escola (PDDE); Programa de Apoio aos Sistemas de Ensino para Atendimento de Jovens e Adultos; Programa Nacional de Apoio ao Transporte Escolar (PNATE) e Programa Brasil Alfabetizado. (ABRANTES, 2010, p.100).
\end{abstract}

Estas transferências automáticas tem os critérios que definem a origem dos recursos e os montantes a serem distribuídos para cada governo especificados em lei ou mesmo na própria Constituição.

\subsubsection{Transferências de Fundo a Fundo}

São repasses regulares e programados de recursos diretamente do Fundo Nacional de Saúde ou do Fundo Nacional de Assistência Social para os Municípios, independentemente de convênio ou instrumento similar. Destina-se ao financiamento das ações estratégicas e serviços de saúde e assistência social.

\subsection{Transferências Voluntárias}

Segundo Abrantes, as transferências voluntárias: 
Compreendem os repasses de recursos correntes ou de capital a outro ente da Federação, a título de cooperação, auxílio ou assistência financeira, que não decorram de determinação constitucional, legal ou os destinados ao Sistema Único de Saúde. A operacionalização dessas transferências é, em regra, viabilizada por meio de convênios ou contratos de repasses. (2010, p.106).

Dessa forma, as transferências voluntárias são os recursos financeiros repassados pela União ou Estados aos Municípios em decorrência da celebração de ato normativo bilateral cuja finalidade é a realização de obras e/ou serviços de interesse comum entre as esferas do Governo.

A lei de responsabilidade fiscal (Lei Complementar nº101, de 4 de maio de 2000) no seu artigo 25 afirma que: Para efeito desta Lei Complementar, entende-se por transferência voluntária a entrega de recursos correntes ou de capital a outro ente da Federação, a título de cooperação, auxílio ou assistência financeira, que não decorra de determinação constitucional, legal ou os destinados ao Sistema Único de Saúde.

\section{GESTÃO PÚBLICA ORÇAMENTÁRIA (GESTÃo DE RECEITAS E DESPESAS)}

A gestão das receitas e despesas, ou gestão orçamentária está regrada nos artigos 165, 166, 167, 168 e 169 da Constituição Federal, constituindo instrumentos de controle e planejamento das verbas municipais na busca da concretização e efetivação da execução das atribuições e competências dos Municípios e na implementação de políticas públicas. Esses mandamentos constitucionais expressão princípios e meios de realização do processo orçamentário.

O orçamento público, que é como veremos a seguir, um importante instrumento de planejamento e execução das finanças públicas que engloba a previsão das receitas e à fixação das despesas públicas. Portanto, o orçamento público prevê estimativa das receitas e autorização para prática de despesas da administração pública direta e indireta em um lapso temporal denominado exercício. O orçamento Público reflete também as decisões políticas, escolhendo as ações prioritárias para o atendimento dos anseios da população, diante da falta de recursos.

Quanto aos Municípios brasileiros a gestão orçamentária se dá pelos preceitos do artigo 165 da CF/88, além da Lei $n^{\circ}$. 4320/1964 e a Lei Complementar $n^{\circ}$ 101/2000 que exigem e regulam a elaboração de leis referentes ao planejamento e ao orçamento, quais sejam: o Plano Plurianual - PPA, a Lei de Diretrizes Orçamentárias - LDO e a Lei Orçamentária Anual - LOA.

A elaboração dessas leis, que são ordinárias, é de iniciativa exclusiva do Prefeito que a partir das suas prioridades políticas e decisões amolda as pretensões orçamentárias advindas das várias fontes de custeio, estabelecendo um projeto de lei que as integra. Essa proposta de lei é submetida Câmara de Vereadores, que a debate, altera, emenda, aprova e envia de volta ao edil municipal para sanção. 
Caso o montante das receitas (tributárias) do ano for superior à prevista, o Poder Executivo municipal encaminha à Câmara Municipal projeto de lei solicitando autorização para incorporar e executar o excedente de arrecadação, que são os créditos adicionais. Ocorrendo de as despesas extrapolarem as receitas, a gestão municipal fica impedida de executar o orçamento em sua integralidade, devendo dessa forma reduzir despesas. Isso por meio de ato administrativo emanado do Prefeito ou através de delegação. No entanto, na prática acontece de maneira informal, através do bloqueio de recursos aos órgãos administrativos ou supressão de serviços ou políticas públicas.

Para os Municípios, a arrecadação dos diversos tributos de sua competência é uma importante fonte de recursos, sobretudo para o custeio das despesas decorrentes da execução dos serviços públicos e da realização do bem comum de toda a população. A arrecadação tributária e as transferências intergovernamentais devem estar inseridas no orçamento municipal para a finalidade de alocar as verbas nas mais variadas áreas em que opera (saúde, educação, meio ambiente, agricultura etc.) evidenciando as ações e prioridades a serem realizadas naquele exercício.

Como vimos anteriormente, o orçamento público municipal baseia-se em três vertentes: no Plano Plurianual (PPA), na Lei das Diretrizes Orçamentárias (LDO) e na Lei de Orçamentária Anual (LOA). Dessa forma, é possível aos Municípios realizarem um planejamento eficaz e racionalizado de suas receitas e despesas a longo, médio e curto prazo.

Há de se observar os prazos definidos na Lei Orgânica do Município para envio dessas leis à Câmara Municipal de vereadores para análise, debate e aprovação. Se ao contrario, não tenham sido determinados os prazos na Lei Orgânica, devem-se cumprir os estabelecidos no artigo 35 do Ato das Disposições Constitucionais Transitórias - ADCT da Constituição Federal de 1988.

O Plano Plurianual-PPA é um plano de médio prazo que busca ordenar a atuação do governo municipal para atingir metas e objetivos delimitados para um quadriênio (quatro anos). Logo é a lei que estabelece as diretrizes, os fins e metas da Administração Pública municipal. Engloba os três últimos exercícios de mandato e o primeiro do mandato posterior para favorecer a continuidade programática entre as administrações. A lei do PPA deverá ser elaborada no primeiro ano do mandato e enviada à Câmara Municipal até 31 de agosto, inseridas as ações governamentais, entre as quais os programas e metas. Quanto às metas, deverão apresentar a descrição, a quantidade e o valor que se deseja gastar em cada exercício. A previsão do PPA está no art. 165 da Constituição Federal. É de fundamental importância para a gestão pública, uma vez que a Lei de Responsabilidade Fiscal diz no art. 15, combinado com os artigos 16, II e 17, $\S 4^{\circ}$ que a criação de despesa que não esteja prevista no PPA, será tida como não autorizada e lesiva ao patrimônio público. 
A Lei de Diretrizes Orçamentárias-LDO é a lei que tem por escopo orientar a elaboração do Orçamento Municipal Anual, abrangendo parte dos programas e metas contidos no PPA. Prevista no artigo 165, inciso II, $\S 2^{\circ}$ e no art. $4^{\circ}$ da Lei Complementar $n^{\circ} 101 / 2000$ (Lei de Responsabilidade Fiscal).

A LDO é a lei que antecede a Lei Orçamentária Anual-LOA. O Prazo para os Municípios elaborarem a LDO é aquele previsto em sua Lei Orgânica. Não havendo regulamentação quanto ao prazo: segue-se o prazo constitucional seguido pela União. Tem como principal fim orientar a preparação dos orçamentos fiscal e da seguridade social e de investimento do governo municipal, abrange os poderes Executivo e Legislativo, e também as entidades da administração direta e indireta, autárquica, fundacional e empresas públicas. Visa adequar a Lei Orçamentária Anual - LOA às diretrizes, objetivos e metas da administração pública que estão inseridas na lei do Plano Plurianual. Integrará o projeto de Lei de Diretrizes Orçamentárias, dois anexos, um anexo contendo as metas fiscais e outro contendo os riscos fiscais.

A Lei Orçamentária Anual-LOA é a lei que estima a receita e autoriza a despesa, sendo o orçamento propriamente dito. É elaborada anualmente pelo Chefe do Poder Executivo em observação ao art. 165, III da Constituição Federal e a Lei Federal 4.320/64, que estabelece as normas gerais para elaboração, execução e controle orçamentário.

A LOA é editada para permitir a efetivação das metas e objetivos estabelecidos no Plano Plurianual. Observa os ditames da Lei de Diretrizes Orçamentárias a qual institui o programa de ações a serem realizadas para alcançarem os fins almejados, cujo implemento se dará durante o exercício financeiro. Segundo o Guia Básico para Gestão nos Municípios:

\footnotetext{
Merece atenção especial do (a) prefeito (a) que irá assumir, haja vista que a execução de seu plano de governo deverá estar em consonância com essa lei. Caso sejam necessárias alterações, deverão ser feitas por meio de abertura de créditos adicionais (suplementares, especiais e extraordinários) Tendo em vista que não poderão ser realizadas despesas sem prévia autorização, caso a LOA não tenha sido aprovada há que se abrir créditos especiais para realização das despesas, nos termos do $\S 8^{\circ}$ do art. 166 da Constituição Federal. (BRASIL, 2008, p.15).
}

A LOA deve ser votada e aprovada até o final de cada sessão legislativa, ou seja, o período anual, em que Câmara Municipal se reúne anualmente, com início e fim no ano civil conforme previsão em Lei Orgânica. Depois de aprovado pelos Vereadores, em seguida a LOA é sancionada e publicada pelo Prefeito Municipal entrando em vigência.

\subsection{Receitas Públicas Municipais}

Segundo o livro Receitas Públicas: manual de procedimentos: aplicado à União, Estados, Distrito Federal e Municípios, conceito de receitas públicas denota: 
Todos os ingressos de caráter não devolutivo auferidas pelo poder público, em qualquer esfera governamental, para alocação e cobertura das despesas públicas. Dessa forma, todo o ingresso orçamentário constitui uma receita pública, pois tem como finalidade atender às despesas públicas. (BRASIL, 2005, p.14)

Tendo em vista esse conceito, compreendem-se entre as receitas públicas municipais os tributos de competência estabelecidos pela CF88 aos Municípios, bem como os valores referentes ao montante composto pelas transferências intergovernamentais.

Relembremos algumas das fontes de receita aqui já estudadas:

a) Os tributos de competência municipal: IPTU; ISS; ITBI; taxas de polícia e taxas de serviços; contribuição de melhoria; contribuição para custeio da iluminação pública-COSIP;

b) As Transferências Intergovernamentais:

b.1) Obrigatórias

b.1.1) Participação no produto da arrecadação federal :Fundo de Participação dos Municípios - FPM, Imposto Territorial Rural - ITR) e a compensação financeira (royalties do petróleo e afins)

b.1.2) Participação no produto da arrecadação estadual :Imposto sobre Circulação de Mercadorias e Serviços - ICMS, Imposto sobre a Propriedade de Veículos Automotores - IPVA

\section{b.2) Voluntárias}

b.2.1) Transferências voluntárias da União e do estado por meio de convênios e contratos de repasse;

b.2.2) Transferências fundo a fundo nas áreas de saúde e assistência social;

b.2.3) Relações com terceiros (públicos ou privados) por meio de convênios, termos de parceria e outros instrumentos.

Após a análise dos tópicos anteriores, iremos nos ater agora à figura das Despesas Públicas.

\subsection{Despesas Públicas Municipais}

Podemos denominar despesas públicas segundo Abrantes como:

Como todos os dispêndios que a Administração Pública faz para o custeio de seus serviços, a remuneração dos servidores, a aquisição de bens, a execução indireta de obras e serviços e outros empreendimentos necessários à consecução de seus fins. (...) Portanto, a despesa pública é o conjunto de gastos que o Estado é obrigado a fazer para desempenhar as funções básicas a ele atribuídas, que atendam os interesses da comunidade tanto na manutenção de serviços que beneficiem diretamente a População quanto na implantação da infraestrutura do desenvolvimento socioeconômico e, também, aqueles para saldar os compromissos da dívida pública. (2010, p. 109) 
A relação entre despesas e receitas é notória. Está última como fonte de custeio, é essencial para a realização e efetivação das políticas públicas e para o incremento da qualidade e satisfação da população na busca pelo bem comum.

A Lei n. 4.320, de 17 de março de 1964 (Lei de Finanças Públicas ou Lei de Normas Gerais sobre Direito Financeiro) classificas as despesas públicas, segundo critérios econômicos e mais interessantes ao nosso estudo despesa orçamentária e despesa extra-orçamentária.

O Manual de Despesa Nacional: Aplicado à União, Estados, Distrito Federal e Municípios do Ministério da Fazenda estabelece, mutatis mutandis, os conceitos de despesa orçamentária e extraorçamentária, ao classificar as despesas públicas quanto à dependência da execução orçamentária em:

\begin{abstract}
a) Despesa resultante da execução orçamentária - aquela que depende de autorização orçamentária para acontecer. Exemplo: despesa com salário, despesa com serviço, etc.

b) Despesa independente da execução orçamentária - aquela que independe de autorização orçamentária para acontecer. Exemplo: constituição de provisão, despesa com depreciação, etc. (BRASIL, 2008, p.13).
\end{abstract}

A diferença entre a despesa orçamentária e a extra-orçamentária reside no fato da primeira exigir, em qualquer hipótese, prévia autorização legislativa para sua efetivação.

\title{
5.2.1 Despesa Pública Orçamentária
}

Como vimos no tópico anterior, depende de previsão em lei orçamentária ou mesmo de créditos adicionais. Dividem-se, segundo a lei 4.320/64, art. 12 e a Portaria Interministerial $\mathrm{n}^{\circ} .325$, de 27 de agosto de 2001, quanto à categoria econômica em:

a)Despesas orçamentárias correntes:

São as despesas que não colaboram, diretamente, para a composição ou aquisição de um bem de capital. Compreendem:

○ Despesas de custeio: Lei 4.320/64, art.12 $§ 1^{\circ}$, são as dotações para manutenção de serviços anteriormente criados, inclusive as destinadas a atender a obras de conservação e adaptação de bens imóveis.

○ Transferências correntes: Lei 4.320/64, art.12,\$2º̃a as dotações para despesas as quais não corresponda contraprestação direta em bens ou serviços, inclusive para contribuições e subvenções destinadas a atender à manifestação de outras entidades de direito público ou privado. Dividem-se em: 
- Subvenções sociais: destinadas a cobrir despesas de custeio de instituições públicas ou privadas de caráter assistencial ou cultural, desde que sem finalidade lucrativa (Lei 4.320/64, art.12 $3^{\circ}$, inciso I);

- Subvenções econômicas: destinadas a cobrir despesas de custeio de empresas públicas de caráter industrial, comercial, agrícola ou pastoril (Lei 4.320/64, art.12 §3º inciso II).

b) Despesas orçamentárias de capital:

São as despesas que contribuem, diretamente, para a formação ou aquisição de um bem de capital. Classificam-se em:

○ Despesas de investimentos: Lei 4.320/64, art.12 $\$ 4^{\circ}$, são as dotações para o planejamento e a execução de obras, inclusive as destinadas à aquisição de imóveis considerados necessários à realização destas últimas, bem como para os programas especiais de trabalho, aquisição de instalações, equipamentos e material permanente e constituição ou aumento do capital de empresas que não sejam de caráter comercial ou financeiro.

○ Inversões financeiras: Lei 4.320/64, art.12 $\$ 5^{\circ}$, Incisos I, II e III, são despesas com aquisição de imóveis, bens de capital já em utilização, aquisição de títulos representativos de capital de entidades já constituídas (quando a operação não importe em aumento de capital), constituição ou aumento de capital de entidades comerciais ou financeiras (inclusive operações bancárias e de seguros).

- Transferências de capital: Lei 4.320/64, art.12, $\S 6^{\circ}$, são as dotações para investimentos ou inversões financeiras que outras pessoas de direito público ou privado devam realizar, independentemente de contraprestação direta em bens ou serviços, constituindo essas transferências auxílios ou contribuições, segundo derivem diretamente da Lei de Orçamento ou de lei especialmente anterior, bem como as dotações para amortização da dívida pública. Podem ser:

- Auxílios: se derivadas da lei orçamentária;

- Contribuições: derivadas de lei anterior à lei orçamentária.

\subsubsection{Despesa Pública Extra-orçamentária}

Conforme vimos anteriormente, já sabemos que as despesas extra-orçamentárias são aquelas que independem de autorização orçamentária para acontecer, uma vez que não consta na lei orçamentária. Em outras palavras as despesas extra-orçamentárias são os pagamentos que não dependem de autorização legislativa, ou seja, não integram o orçamento público. Resumem-se a devolução de valores arrecadados. 


\section{ADMINISTRAÇÃO TRIBUTÁRIA DOS MUNICÍPIOS: UMA ANÁLISE DE RESULTADOS}

A administração tributária é a atividade do Poder Público que realiza a fiscalização e arrecadação tributária através dos procedimentos de verificação quanto à ocorrência do fato gerador e o cumprimento das obrigações tributárias, fazendo o lançamento tributário que irá iniciar a cobrança das exações. Constitui também atribuição da administração tributária expedição de certidões negativas ou positivas que comprovem a situação fiscal do sujeito passivo quanto à ausência ou não de pendências tributárias. O código Tributário Nacional prevê no artigo 194 e seguintes, no título Administração Tributária, o regramento pertinente aos órgãos e agentes da administração tributária.

Ricardo Alexandre ao discorrer sobre o assunto afirma a respeito da administração tributária que "a atividade de fiscalizar e arrecadar tributo é, talvez, a mais importante atividade-meio do Estado, pois dos recursos dela advindos dependem todas as atividades-fim estatais, como a prestação dos serviços de segurança, saúde e educação”. (2013, p. 504)

Corroborando esse entendimento, a Constituição Federal em seu artigo 37, inciso XXII combinado com o artigo 167, inciso IV reitera que as administrações tributárias são atividades essenciais à atividade e funcionamento dos Entes Federados, devendo ser exercidas por servidores de carreiras específicas, com recursos prioritários para a realização de suas atividades, podendo até vincular a receita dos próprios impostos para tal finalidade.

Uma vez definida os objetivos e a importância da administração tributária, vamos saber quem são os órgãos e agentes que compõem o quadro de responsáveis pela transformação em atos concretos das regras abstratamente previstas na legislação tributária. Iremos nos ater essencialmente à municipalidade em nosso estudo. Restringindo-se aos órgãos administrativos e agentes públicos que cuidam da fiscalização e arrecadação tributária dos Municípios.

Falaremos inicialmente dos agentes públicos atuantes na administração tributária municipal.

Para Meirelles (2005, p. 75) “agentes públicos são todas as pessoas físicas incumbidas, definitiva ou transitoriamente, do exercício de alguma função estatal”.

De acordo com a classificação e conceituação de Marcelo Alexandrino e Vicente Paulo (2013, p.124-126). Os agentes públicos são divididos nas seguintes categorias principais que interessam a nosso estudo:

a) Agentes Políticos: são todos os detentores de mandato eletivo (prefeitos e vereadores) e os agentes de primeiro escalão (secretários municipais);

b) Agentes Administrativos: são todos aqueles que exercem uma atividade pública de natureza profissional e remunerada, sujeitos à hierarquia funcional e ao regime jurídico estabelecido pelo 
ente federado ao qual pertencem. Ocupantes de cargos públicos, empregos públicos e de funções públicas nas Administrações Direta e Indireta das unidades da Federação, nos três Poderes. E subdividem-se em:

b.1) Servidores Públicos: são os agentes administrativos que mantém vínculo estatutário (não contratual) com a Administração. Podendo ser servidores públicos efetivos (titulares de cargos efetivos mediante concurso público) ou servidores públicos comissionados (cargos em comissão livremente nomeados e exonerados).

b.2) Empregados Públicos: são agentes administrativos que possuem emprego público, com regime contratual e celetista, com ingresso mediante concurso público e podem adquirir estabilidade.

b.3) Temporários: são os agentes administrativos contratados por tempo determinado para atender a necessidade temporária de excepcional interesse público. Exercem função pública, com vínculo contratual de natureza jurídico-administrativa.

Diante dessa classificação, na administração pública municipal apenas o Prefeito e os seus Secretários seriam agentes políticos, logo não seriam considerados agentes políticos, os diretores, subsecretários, chefes de departamentos, gerentes de setor e outros cargos de confiança. Esses passariam a compor a categoria de servidores públicos efetivos ou comissionados, conforme o caso.

Já vimos anteriormente no inicio deste tópico que a Constituição Federal em seu artigo 37, inciso XXII combinado com o artigo 167, inciso IV ordena que os servidores públicos que atuam na administração tributária devem ocupar cargos públicos, criados e definidos por lei, com denominação própria e específica daquele órgão. Esta mesma lei deve delinear as atribuições dos cargos e fixar o padrão de vencimentos, remunerações e garantir as gratificações relacionadas à atividade.

Cabe aos Municípios legislar sobre a estrutura dos órgãos da administração tributária que podem ser exercidos de acordo com a natureza da função por servidores que exercem atividades em cargos 'de linha', de apoio ou de atividades genéricas. Cargos 'de linha' ou finalísticos são os que agem diretamente na arrecadação e fiscalização, como os auditores, analistas e agentes fiscais tributários, procuradores fiscais e outras designações contidas na legislação tributária municipal. Cargos de apoio ou suporte são os servidores que atuam na base, dando ajuda em tarefas internas, que guardam estreita relação com os que atuam na linha de frente, a exemplo dos assistentes administrativos fiscal. Cargos de atividades genéricas abrangem as funções não específicas da administração tributária municipal, como motorista, contabilista, auxiliar administrativo entre outros.

O Código Tributário Nacional define como sendo atribuições da Administração Tributária a fiscalização (arts. 194 a 200), a dívida ativa com providências executórias contra os que não cumpriram suas obrigações (arts. 201 ao 204) e a expedição de certidões negativas ou positivas para a comprovação da regularidade fiscal dos sujeitos passivos possibilitando o acesso a benefícios legais (arts. 205 ao 208). 


\title{
6.1. Análise da Arrecadação Tributária dos Municípios Brasileiros e Apontamentos para a Eficiência
} da Arrecadação

Na monografia vencedora do XV Prêmio Tesouro Nacional em Tópicos Especiais de Finanças Públicas de autoria de Rodrigo Octávio Orair e André Amorim Alencar (2010, p.33) ao analisarem 5.564 Municípios brasileiros, utilizando o método de cluster com dados do Finanças do Brasil: (FINBRA) dados contábeis dos Municípios organizado pela Secretaria do Tesouro Nacional. Levaram-se em conta os dados do período de 2000-2009, e verificou-se nesse período que:

\begin{abstract}
As análises também mostram que, isolando-se o efeito dos demais fatores, a existência de cadastros informatizados do ISS e do IPTU e de Planta Genérica de Valores tem impactos positivos e significativos sobre a arrecadação própria. Esses resultados evidenciam, portanto, que as medidas administrativas ligadas à modernização da estrutura tributária podem provocar ganhos na arrecadação sem necessariamente modificar as alíquotas.

Em relação às variáveis de localização, os municípios das regiões metropolitanas e as capitais tendem a obter maior arrecadação do que os demais municípios, isolando os demais fatores. Contudo, seus efeitos sobre o ISS e o IPTU são diferenciados. Os resultados encontrados sugerem que a arrecadação do IPTU nas capitais é maior do que nos outros municípios de regiões metropolitanas, enquanto a arrecadação do ISS é menor. Uma possível explicação é o fato de que os municípios das regiões metropolitanas fazem uso do ISS para atrair empresas prestadoras de serviços, aumentando sua arrecadação e reduzindo-a nas capitais, como abordado na seção anterior.

Outros efeitos diferenciados foram encontrados para as variáveis referentes às grandes regiões. A localização dos municípios nas Regiões Sul e Sudeste tende a favorecer a arrecadação do IPTU em relação às demais regiões. A arrecadação do ISS, por sua vez, tende a ser maior nas Regiões Norte e Nordeste, após controlada pelos efeitos dos demais fatores, enquanto a arrecadação das demais receitas tributárias tende a ser maior na Região Centro-Oeste. Vemos assim evidências de um padrão regional da arrecadação tributária. As regressões também corroboram a hipótese levantada em teoria de que municípios localizados em fronteira tendem a arrecadar menos. No caso dos municípios de costa, as estimativas indicam influência positiva sobre a arrecadação de IPTU e negativa para o ISS. (Orair; Alencar, 2010, p. 33).
\end{abstract}

Como exposto em capítulos anteriores, o Município possui uma diversidade de fontes de receita. Precisa-se analisar a legislação tributária municipal para saber se acolhe à melhor técnica e permite arrecadar os tributos de modo a congregar eficiência e justiça fiscal.

O conhecimento sobre outros Municípios também pode ser útil na identificação de inovações e experiências que deram certo. São apontamentos importantes para a melhoria da gestão tributária e efetivação da autonomia dos Municípios brasileiros:

a) A simplificação da legislação tributária e o exercício efetivo da competência tributária dos Municípios em conformidade com o artigo 11 da Lei de Responsabilidade Fiscal. É importante examinar se o Código Tributário Municipal e as demais leis tributárias encontram-se de acordo com as normas constitucionais e legais e se a administração tributária está organizada de modo a cumprir suas atribuições e alcançar os objetivos que fundamentam a arrecadação. 
b) A busca pela qualificação profissional do quadro de pessoal composto pelos agentes públicos integrantes das carreiras especificas da administração tributária, e implementação de gestão pessoal pautada em incentivos de produtividade;

c) Investimentos massivos em informatização para a composição de dados atualizados e eficientes que ajudaram na fiscalização e lançamentos tributários;

d) Políticas e programas de informação e transparência fiscal aos contribuintes, além de uso de meios de premiação, para incentivar os sujeitos passivos a colaborarem com a administração tributária;

e) Medidas de enfrentamentos à evasão fiscal e agilidade e eficiência na cobrança administrativa e judicial da dívida ativa evitando-se a sonegação fiscal e a perda de receitas.

Neste ínterim existem iniciativas governamentais que estimulam e visam a melhor a gestão tributária dos Municípios brasileiros. O Programa de Modernização da Administração Tributária e de Gestão dos Setores Sociais Básicos-PMAT com recursos do Banco Interamericano de Desenvolvimento e o Programa Nacional de Apoio à Administração Fiscal para os Municípios Brasileiros-PNAF do Banco Nacional de Desenvolvimento Econômico e Social-BNDES são linhas de financiamento para a modernização da administração tributária e melhoria da qualidade do gasto público em uma perspectiva de desenvolvimento local. Tem foco na modernização das prefeituras, sobretudo quanto à eficiência administrativa e informatização dos sistemas de fiscalização e arrecadação tributária municipal. Proporcionando aos Municípios uma gestão de qualidade que gere aumento de receitas e redução, através de medidas de eficiência, do custo unitário dos serviços públicos prestados à população.

\section{CONDIDERAÇÕES FINAIS}

Apesar dos Municípios brasileiros possuírem fontes de custeio das despesas que decorrem do incremento de suas atribuições e competências pelo advento da Constituição Federal, notamos que a imensa maioria, sobretudo as menores municipalidades nos rincões do Brasil, longe estão de concretizar o princípio da autonomia pela suficiência de recursos próprios oriundos dos tributos de sua competência constitucional. Esse cenário torna-se mais agravante em razão da dependência desses Municípios dos repasses e transferências de esferas governamentais federais e estaduais. Para efetivação do federalismo fiscal é necessário aumentar a capacidade de arrecadação dos Municípios, visando uma menor dependência das transferências intergovernamentais. Este é um desafio a ser superado, ainda mais quando esbarra com a mentalidade quase generalizada de que "os prefeitos não gostam de cobrar tributos", talvez, em razão das consequências político-eleitoreiras do incremento da carga tributária aos cidadãos contribuintes que também são eleitores em época de pleito. 
Muitos prefeitos acreditam que a arrecadação própria no montante da receita é, geralmente, muito baixa para os pequenos Municípios, fazendo com que o risco político-eleitoral do esforço fiscal para esses seja desinteressante.

Percebemos também que a maior parte dos Municípios enfrenta dificuldades na fiscalização e arrecadação tributária e a solução apontada seria a priorização de meios para incrementar a eficiência nas atividades da administração tributária municipal, realizando a competência tributária com o máximo de tributos que a legislação e a base econômica possibilitam, em prazos adequados e com maior justiça fiscal.

Quando se fala em justiça fiscal, nos referimos a usar o sistema fiscal para reduzir desigualdades. Com tratamento igual para os que são iguais e diferente para os que são diferentes em consonância ao princípio da igualdade tributária. Também estamos falando da estrutura dos gastos públicos. A maneira como os tributos são arrecadados, assim como depois são gastos os recursos públicos.

Ao propor alternativas como: a modernização e informatização da estrutura arrecadatória; a simplificação da legislação tributária e efetivação da competência tributária; uma melhor gestão, com base na qualificação e eficiência do quadro de pessoal da administração tributária; a troca de experiências positivas entre as administrações dos diversos municípios; programas de conscientização e incentivo para os contribuintes com fins à cidadania fiscal; combate a evasão e sonegação fiscal e corrupção visando a diminuir perdas fiscais. Tudo isso implica em maior eficiência e celeridade na Administração Tributária dos Municípios e tem como consequência ganhos de arrecadação, sem necessariamente onerar os contribuintes, sejam pessoas físicas ou jurídicas.

É dominante o pensamento de que o sistema tributário brasileiro é um dos mais complexos do mundo, isso em face da grade de tributos existentes e das diversas exigências quanto às obrigações acessórias. Quanto a isso, a adoção pelas Administrações tributárias Municipais das medidas aqui sugeridas colabora para abrandar tal imagem negativa exigindo assim menos esforço dos contribuintes para cumprir todos os encargos correlatos. Além de desburocratizar e tornar mais prática a cobrança das exações cooperando de forma positiva para a eficiência da máquina administrativa e tendo como consequência uma melhor arrecadação. Assim, gera-se aumento de receitas para custear os programas políticos e os serviços públicos contribuindo para a autonomia municipal em face da dependência de outras receitas não próprias.

Não se trata aqui de criar ou aumentar novos tributos, mas tão somente de efetivar os existentes já definidos na Lei Suprema, e tornar a administração tributária municipal mais eficiente na fiscalização e arrecadação desses tributos. Uma melhor arrecadação traz inúmeros benefícios e poderá retornar para a população melhores serviços públicos e infraestrutura urbana e rural. 


\section{REFERÊNCIAS}

ABRANTES, Luiz Antônio; FERREIRA, Marco Aurélio Marques. Gestão tributária. Florianópolis: Departamento de Ciências da Administração / UFSC; [Brasília]: CAPES: UAB, 2010.126p. : il.

AFONSO, José Roberto Rodrigues et al. Municípios, arrecadação e administração tributária: quebrando tabus. Revista do BNDES, Rio de Janeiro: BNDES, v. 5, n. 10, p. 3-36, dez. 1998a.

ALEXANDRE, Ricardo. Direito Tributário Esquematizado. -7. ed. rev. e atual. - Rio de Janeiro: Forense; São Paulo: MÉTODO, 2013.

ALEXANDRINO, Marcelo; PAUlO, Vicente. Direito Administrativo descomplicado. $21^{\text {a }}$ ed. - Rio de Janeiro: Forense; São Paulo: MÉTODO:2013.

BRASIL. Ministério da Fazenda. Secretaria do Tesouro Nacional. Manual de Despesa Nacional. Brasília: STN/Coordenação-Geral de Contabilidade, 2008. 120p.

BRASIL. Ministério da Fazenda. Secretaria do Tesouro Nacional. Receitas Públicas: manual de procedimentos. Brasília: Secretaria do Tesouro Nacional, 2005 - Anual.

BRASIL. Presidência da República. Guia Básico para Gestão nos Municípios. Brasília: MP, 2008.44p.

CARRAZZA, Roque Antonio. Curso de Direito Constitucional Tributário. 29a edição, revista, ampliada e atualizada. São Paulo: Malheiros Editores, 2013.

IBGE/DPE/COPIS. Estimativas populacionais para os municípios brasileiros em 01.07.2013. Disponível em <http://www.ibge.gov.br/home/estatistica/populacao/estimativa2013/estimativa_dou.shtm>. Acesso em: 10 de fevereiro de 2015

MEIRELLES, Hely Lopes. Direito Administrativo Brasileiro. $31^{\mathrm{a}}$ ed. São Paulo: Malheiros Editores. 2005.

Mini código Saraiva: tributário nacional, Constituição Federal e Legislação Complementar / obra coletiva de autoria da Editora Saraiva com a colaboração de Luiz Roberto Curia, Lívia Céspedes e Juliana Nicoletti. - 20. ed -São Paulo: Saraiva, 2014.

ORAIR, Rodrigo Octávio; ALENCAR, André Amorim. Esforço fiscal dos Municípios: indicadores de condicionalidade para o sistema de transferências intergovernamentais. In: Finanças públicas: XV Prêmio Tesouro Nacional - 2010. - Brasília: STN, 2010

PAULO, Vicente; ALEXANDRINO, Marcelo. Direito Constitucional descomplicado. 11. Ed. - Rio de Janeiro: Forense; São Paulo: MÉTODO: 2013.

RIBEIRO, Marcelo Gollo. Aspectos da gestão tributária no Município. Jus Navigandi, Teresina, ano 16, n. 2850, 21 abr. 2011. Disponível em:<http://jus.com.br/artigos/18947>. Acesso em: 5 out. 2014.

SILVA, Albertiano Dias da. Gestão tributária dos municípios brasileiros: a busca da autonomia municipal. 2015. 42f. Monografia (Especialização em Gestão Pública) - Universidade Estadual da Paraíba, João Pessoa, 2015. 
TRISTÃO, José Américo Martelli. A Administração Tributária dos Municípios Brasileiros: uma avaliação do desempenho da arrecadação. São Paulo: EAESP/FGV, 2003. 172 p. 